\title{
Thin films with chemically graded functionality based on fluorine polymers and stainless steel
}

\author{
A.P. Piedade*, J. Nunes, M.T. Vieira \\ ICEMS, Departamento de Engenharia Mecânica, Faculdade de Ciências e Tecnologia da Universidade de Coimbra, \\ Rua Luís Reis Santos, 3030-788 Coimbra, Portugal
}

Received 19 October 2007; received in revised form 8 January 2008; accepted 26 February 2008

Available online 14 March 2008

\begin{abstract}
Thin films of stainless steel and poly(tetrafluoroethylene) were co-deposited, by radiofrequency magnetron sputtering, in an inert atmosphere in order to produce a functionally graded material as a coating on a traditional biomaterial, where non-ferromagnetic characteristics and improved wettability must be ensured. These thin films are intended to modify the surface of SS316L used in stents, where the bulk/thin film couple should be regarded as a single material. This requires excellent adhesion of the coating to the substrate. All coatings were deposited with an average thickness of $500 \mathrm{~nm}$. The chemical and phase characterization of the surface revealed that, with the increase in $\mathrm{F}$ content, the thin film evolves from a ferritic phase $(\alpha)$ to an amorphous phase with dispersion of a new crystalline ceramic phase $\left(\mathrm{FeF}_{2}\right)$. For intermediate $\mathrm{F}$ content values, an austenitic (1 111$)$ phase $(\gamma)$ was present. Bearing in mind the envisaged application, the best results were attained for thin films with a fluorine content between 10 and 20 at.\%.
\end{abstract}

(C) 2008 Acta Materialia Inc. Published by Elsevier Ltd. All rights reserved.

Keywords: Functionally graded coatings; PTFE; 316L; Stents

\section{Introduction}

Stainless steel is the most commonly used material for stent fabrication, but restenosis associated with thrombosis at sites of stent placement remains an important clinical problem [1,2]. As some authors have pointed out [3], it is likely that the migration of arterial endothelial cells from the adjacent tissue along with protein adsorption by metals and polymers used for fabricating stents are the predominant sources of these problems. For these reasons, research is being carried out with the aim of producing a variety of modifications to stents to avoid restenosis and thrombogenicity. In addition to the use of new bulk metallic materials [4-6], some attempts have been made to work with biodegradable or bioresorbable polymers, but the mechanical collapse of these materials is a problem [7]. Moreover, several distinct surface coatings using different materials such

\footnotetext{
${ }^{*}$ Corresponding author. Tel.: +351 239790 700; fax: +351 239730701 . E-mail address: ana.piedade@dem.uc.pt (A.P. Piedade).
}

as gold [8,9], heparin [10], phosphorylcholine [11] and diamond-like carbon (DLC) $[12,13]$ have been applied to conventional stents in order to reduce allergic responses and thrombus formation. Despite these efforts, only a small number of the developed systems possess the physical characteristics that make them useful as implant medical devices that undergo flexion or expansion. One of the most promising stent surface modifications aims to achieve improved mechanical performance of the stent with the additional ability to deliver pharmacological drugs at the stent implantation site. Within this line of research, drugeluting stents have been developed $[14,15]$ but, once again, the coating that carries and releases the drugs is usually a polymer $[16,17]$. These types of coating present two main limitations. First, the surface has an unpredictable degradation kinetic during drug release, as each clinical case is unique. Secondly, a more pertinent problem is the mismatched properties between the polymeric coating and the underlying metallic substrate during the lifetime of a stent. 
For the stated reasons, the modification of traditional metallic stents with a coating that could simultaneously possess very strong adhesion to the substrates previously defined as well as good ductility would present an important step towards the reduction of restenosis and at lower cost. Compatibility with the endothelium vascular wall and, if needed, with appropriate chemical groups that allow the immobilization of biological compounds or pharmaceutical drugs is also very important. The aim of this study is to develop a 'new' coating based on functionally graded material (2D-FGM) from $100 \%$ metal alloy (stent) to $100 \%$ polymer (PTFE). Nevertheless, no information is available concerning the characteristics of a thin film resulting from the co-deposition of these two materials, although the use of fluorine in cardiovascular implants has already been reported, for example, in the development of a biodegradable stent made from resorbable $\mathrm{Mg}$ alloy with a $\mathrm{MgF}_{2}$ coating [18]. In this study, the first step is to understand the effect of increasing content of fluorine/ carbon on the properties of homothetic coatings based on the chemical composition of traditional bulk material stents.

\section{Experimental}

\subsection{Deposition technique}

The sputtered thin films were deposited using a radiofrequency (RF) power supply of 1000 and $500 \mathrm{~W}$, branched to the two assisted magnetron targets and substrate holder, respectively. Stainless steel AISI (SS316L) and poly(tetrafluoroethylene) (PTFE) targets $100 \mathrm{~mm}$ in diameter were used. The parameters used in the deposition were: $10^{-4} \mathrm{~Pa}$ ultimate vacuum pressure; $5.1 \mathrm{~W} \mathrm{~cm}^{-2}$ discharge power density for SS316L and from 0 to $1.3 \mathrm{~W} \mathrm{~cm}^{-2}$ for PTFE; 0.7 Pa total discharge pressure; and 15 min deposition time. The thin films were deposited onto glass lamellae $(R a=0.002 \mu \mathrm{m})$ and $\mathrm{SS} 316 \mathrm{~L}$ substrates. The metallic material was polished with $\mathrm{SiC}$ paper grit down to 2500 and with $1-\mu \mathrm{m}$-grain-size diamond paste to $R a=0.02 \mu \mathrm{m}$.

\subsection{Characterization techniques}

Cameca SX50 electron probe microanalyser (EPMA) equipment with two wavelength dispersive spectrometers (WDS) was used to assess the chemical composition of both bulk and thin films. An accelerating voltage of $5 \mathrm{keV}$ and a current of $40 \mathrm{nA}$ were chosen for standard calibration and analysis, to ensure the integration of the signals from the thin films only. The X-ray photoelectron spectroscopy (XPS) analyses were performed in a VGESCLAB 250iXL spectrometer. The pressure in the analysis chamber was kept $<5 \times 10^{-8} \mathrm{~Pa}$, and the analyses were performed using monochromatic radiation $\mathrm{Al} \mathrm{K} \alpha$ $(h v=1486.92 \mathrm{eV})$. The photoelectrons were collected at an angle of $90^{\circ}$ with respect to the surface of the samples. The energy step was $20 \mathrm{eV}$ for the survey spectra and
$0.05 \mathrm{eV}$ for the high-resolution spectra. All spectra were referenced to $\mathrm{C}-\mathrm{C}$ at $285 \mathrm{eV}$ in the $\mathrm{C} 1 \mathrm{~s}$ spectrum. After a Shirley-type background subtraction, the peaks were separated using a non-linear least-mean-square program. The atomic percentages were obtained using the sensitivity factors of the Scofield library. The XPS was also used for the in-depth analysis of the thin films. The morphology of both the surface and cross-section of the as-deposited thin films was observed in a Hitachi FEG-SEM S4100 with a spatial resolution of $1.5 \mathrm{~nm}$. This technique was also used to assess the thin film thickness by measuring it in the cross-section observation. The structure was evaluated by X-ray diffraction (XRD). The XRD spectra were obtained using a Philips X'Pert with Co radiation $\left(\lambda_{\mathrm{k} \alpha 1}=1.78896 \AA\right.$ and $\lambda_{\mathrm{k} \alpha 2}=1.79285 \AA$ ), a collimated detector and Bragg-Brentano geometry. All the tests were performed with a step size of $0.025^{\circ}$ and a time per step of $0.5 \mathrm{~s}$. Scratch-test equipment (CSEM Revetest) was used to evaluate the adhesion of the coatings. The scratch tests were performed under standard dynamic conditions [19]: diamond tip radius, $R=0.2 \mathrm{~mm}$; scratching speed, $\mathrm{d} x / \mathrm{d} t=10 \mathrm{~mm} \mathrm{~min}^{-1}$; and loading rate, $\mathrm{d} L / \mathrm{d} t=100 \mathrm{~N} \mathrm{~min}{ }^{-1}$. The load was progressively applied to a maximum value of $70 \mathrm{~N}$. Critical loads were obtained by averaging the results of four different scratches. The hardness measurements were performed in a depth-sensing indentation system Fisherscope H100 with a Vickers indenter [20]. The tests were conducted at a maximum load of $20 \mathrm{mN}$, which ensured that only the deposited thin films were integrated during the indentation. The results are the average value of 10 determinations by sample. The testing procedure, including the correction of the experimental results for geometric defects in the indenter and thermal drift of the equipment, has been described elsewhere [21].

The wettability characteristics of both bulk and thin films were assessed by measuring the static contact angle of the surfaces with $10 \mu 1$ of distilled and deionized water in a DataPhysics QCA-20 apparatus. For each sample, a minimum of 10 measurements was taken, after allowing the system (air/water/surface) to reach equilibrium, and the average value calculated. The values of the contact angles were used to calculate the water adhesion tension $\tau^{0}$, with $\tau^{0}=\gamma^{0} \cos \theta$, where $\gamma^{0}$ is the surface tension of pure water and $\theta$ is the contact angle value.

\section{Results and discussion}

\subsection{Chemical composition and structural features}

The designation, thickness and chemical composition (EPMA) of SS316L stainless steel thin films co-deposited with PTFE is listed in Table 1. A clear trend is observed as the deposition density $\left(d_{\mathrm{dep}}\right)$ of the PTFE target increases, and the $\mathrm{C} / \mathrm{F}$ ratio decreases from 1.7 to 0.1 . If authors are unanimous when the $\mathrm{C} / \mathrm{F}$ ratio values are higher than those of bulk PTFE (0.5), this is not the case when the $\mathrm{C} / \mathrm{F}$ ratio is $<0.5$. However, the co-deposition 
Table 1

Deposition parameters and chemical composition (EPMA) of the thin films co-deposited from SS316L and PTFE targets

\begin{tabular}{|c|c|c|c|c|c|c|c|c|c|}
\hline \multirow[t]{2}{*}{ Film } & \multirow[t]{2}{*}{ Thickness $(\mu \mathrm{m})$} & \multicolumn{2}{|c|}{ Power density $\left(\mathrm{W} \mathrm{cm}^{-2}\right)$} & \multicolumn{5}{|c|}{ Chemical composition (at.\%) } & \multirow{2}{*}{$\begin{array}{l}\mathrm{C} / \mathrm{F} \\
\text { Ratio }\end{array}$} \\
\hline & & $316 \mathrm{SS}$ & PTFE & $\mathrm{Fe}$ & $\mathrm{Cr}$ & $\mathrm{Ni}$ & $\mathrm{C}$ & $\mathrm{F}$ & \\
\hline $\mathrm{SF}_{0}$ & 0.5 & 5.1 & - & 70.7 & 16.3 & 9.4 & 3.6 & - & - \\
\hline $\mathrm{SF}_{1}$ & 0.5 & 5.1 & 0.30 & 64.1 & 14.2 & 10.5 & 7.1 & 4.1 & 1.7 \\
\hline $\mathrm{SF}_{2}$ & 0.6 & 5.1 & 0.40 & 63.9 & 13.5 & 7.9 & 8.9 & 5.8 & 1.5 \\
\hline $\mathrm{SF}_{3}$ & 0.4 & 5.1 & 0.50 & 56.4 & 12.2 & 8.3 & 12.0 & 11.1 & 1.1 \\
\hline $\mathrm{SF}_{4}$ & 0.4 & 5.1 & 0.60 & 46.7 & 9.9 & 7.0 & 16.3 & 20.1 & 0.8 \\
\hline $\mathrm{SF}_{5}$ & 0.5 & 5.1 & 0.75 & 24.4 & 5.2 & 3.6 & 24.4 & 42.4 & 0.6 \\
\hline $\mathrm{SF}_{6}$ & 0.7 & 5.1 & 0.95 & 18.9 & 4.2 & 3.1 & 20.2 & 53.6 & 0.4 \\
\hline $\mathrm{SF}_{7}$ & 0.6 & 5.1 & 1.25 & 22.5 & 4.7 & 6.1 & 5.3 & 61.4 & 0.1 \\
\hline
\end{tabular}

of this polymer with stainless steel has never been reported. In order to evaluate the types of chemical bonds present, XPS analyses were performed at the surface of the deposited thin films (Fig. 1). The $\mathrm{C}$ 1s (Fig. 1a) and $\mathrm{F}$ 1s (Fig. 1b) core-level spectra revealed that no peaks were found that could be identified as the $\mathrm{C}-\mathrm{F}$ binding energy of polymeric chains. These results indicate that there is no formation of oligomeric segments, normally resulting from the scission of $-\left(\mathrm{CF}_{2}\right)_{n}-$ due to the sputtering of PTFE. Thus, all the $\mathrm{C}-\mathrm{F}$ bonds were broken during the sputtering process, and no recombination occurred at the substrate, enabling the formation of compounds which
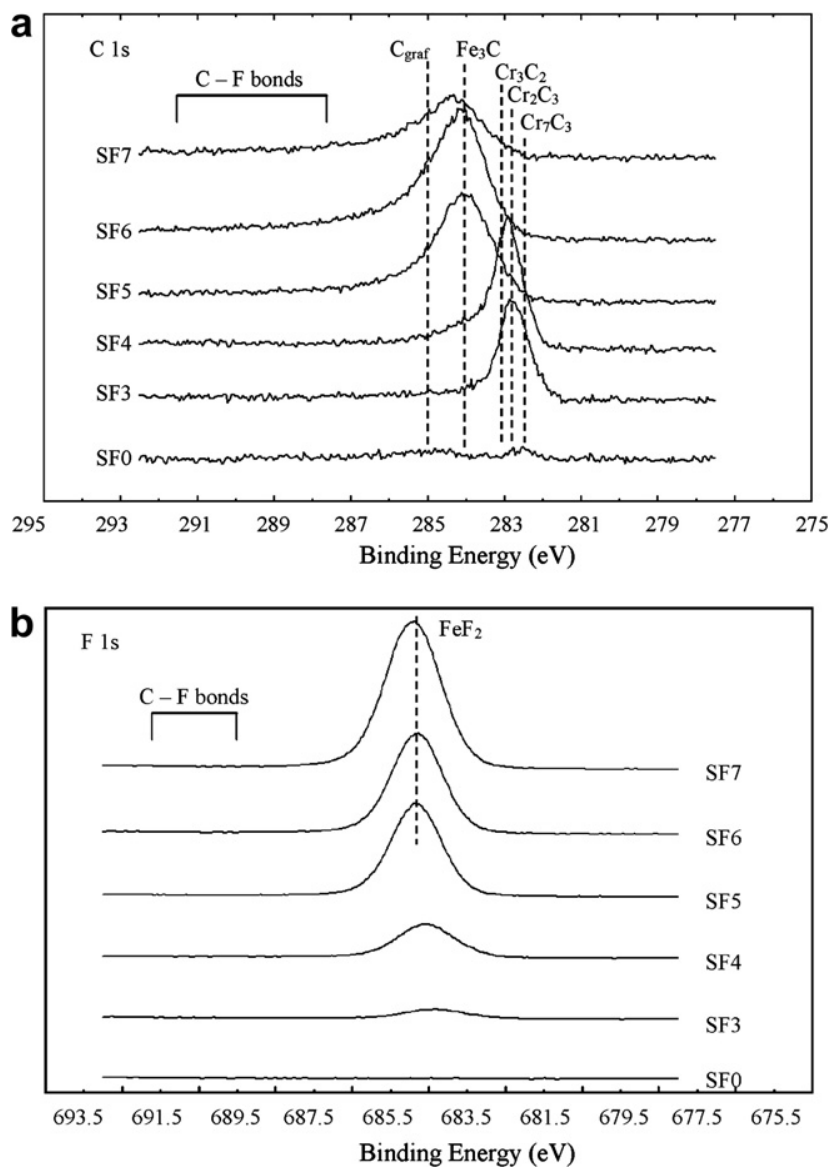

Fig. 1. (a) C 1s and (b) F 1s XPS core-level spectra of all the deposited thin films. are deficient in $\mathrm{F}$ with unsaturated bonds [22,23]. In this study, C, F, Fe and $\mathrm{Cr}$ are the main elements present in the deposition stage. The relative content of each element and the $\Delta_{f} G^{0}$ of possible compounds determine the resulting chemical and phase compositions. The reaction between $\mathrm{C}$ and $\mathrm{F}$ is always unfavourable when compared with the reaction of $\mathrm{F}$ with $\mathrm{Fe}$ to form $\mathrm{FeF}_{2}\left(\Delta_{f} G^{0}=\right.$ $-668 \mathrm{~kJ} \mathrm{~mol}^{-1}$ ) [24] and $\mathrm{C}$ with $\mathrm{Cr}$ to form chromium carbides, for example, $\mathrm{Cr}_{7} \mathrm{C}_{3}\left(\Delta_{f} G^{0}=-177 \mathrm{~kJ} \mathrm{~mol}^{-1}\right)$ [25]. In fact, when the PTFE target has a lower power density, the main compounds found in the 2D-FGM are iron fluoride $\left(\mathrm{FeF}_{2}\right)$ and chromium carbides $\left(\mathrm{Cr}_{7} \mathrm{C}_{3}, \mathrm{Cr}_{3} \mathrm{C}_{2}\right.$ and $\mathrm{Cr}_{2} \mathrm{C}_{3}$ ). Fig. 2 shows the high-resolution XPS spectra of the four elements for the $\mathrm{SF}_{3} 2 \mathrm{D}-\mathrm{FGM}$, which is representative of the thin films deposited when the PTFE target has a lower deposition power. The deconvolution of the highresolution spectra of all the deposited 2D-FGM permitted the identification and relative quantification of the compounds present in each thin film. From the $\mathrm{F}$ data, it is clear that the entire quantity of available element is consumed in the formation of $\mathrm{FeF}_{2}$ and, when PTFE power density increases, no $\mathrm{FeF}_{3}$ phase was observed, as it is a very unstable compound. This has been noted by other authors who deposited iron fluoride thin films from $\mathrm{FeF}_{2}$ and $\mathrm{FeF}_{3}$ targets [26]. While in the first case only the $\mathrm{FeF}_{2}$ phase was found, in the second a mixture of $\mathrm{FeF}_{2}$ and $\mathrm{FeF}_{3}$ was identified. From the $\mathrm{C}$ data, it is possible to observe that the carbon evolution is different with increasing PTFE target power density. While the carbon content increases and the $\mathrm{Cr}$ content is $>10$ at. $\%$ (from $\mathrm{SF}_{0}$ to $\mathrm{SF}_{4}$ ), the main compounds are chromium and iron carbides. For $\mathrm{SF}_{5}$, although the carbon concentration is the highest of the evaluated systems ( 24 at.\%), the carbon only appears in the form of $\mathrm{Fe}_{3} \mathrm{C}$ and small chains such as $\mathrm{CH}_{2} \mathrm{CO}$. The reason for this change can be attributed to the low chromium content, which is present in the form of chromium oxides. In fact, peaks identified as $\mathrm{Cr}_{2} \mathrm{O}_{3}$ $(276.2 \mathrm{eV})$ and $\mathrm{CrO}_{3}(578.1 \mathrm{eV})$ [27] are present in all the high-resolution XPS spectra of $\mathrm{Cr} 2 \mathrm{p}$ owing to the fact that the formation of these compounds is expected $\left(\mathrm{Cr}_{2} \mathrm{O}_{3}\right.$, $\left.\Delta_{f} G^{0}=-1058 \mathrm{~kJ} \mathrm{~mol}^{-1}\right)$ [24]. As PTFE target power density increases further $\left(\mathrm{SF}_{6}\right.$ and $\left.\mathrm{SF}_{7}\right)$ and $\mathrm{Cr}$ and $\mathrm{Fe}$ decrease even more, small $\mathrm{CH}_{2}-\mathrm{CO}$-type chains and graphite are the only peaks identified. In these thin films, all the Fe forms 

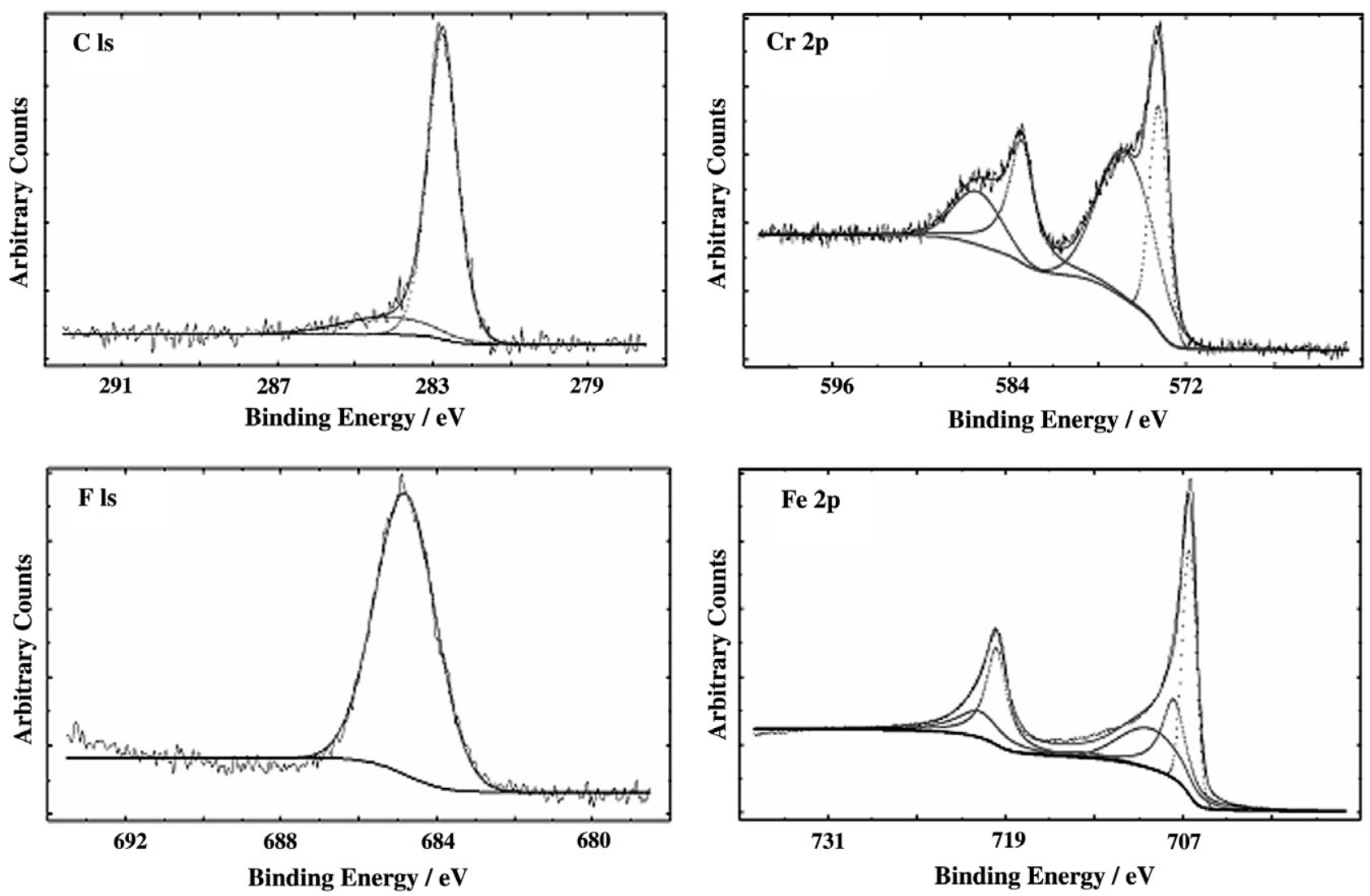

Fig. 2. High-resolution XPS spectra of the major elements of $\mathrm{SF}_{3}$ sample.

iron fluoride, and no $\mathrm{Fe}$ is available for the formation of $\mathrm{Fe}_{3} \mathrm{C}$. Thus, with no $\mathrm{Cr}$ or Fe to react with, carbon 'selfreacts' to form graphite, but it is mainly removed from the sputtering chamber by the pumping system, and this explains why the $\mathrm{C}$ content decreases abruptly in these two thin films, while $\mathrm{F}$ concentration continues to increase.

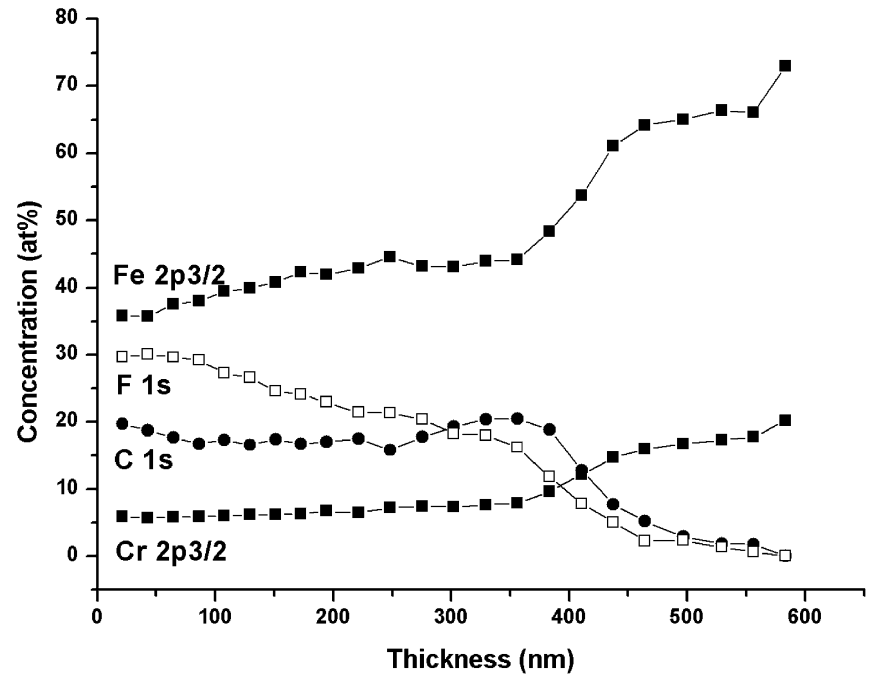

Fig. 3. Chemical composition gradient analysed in sample $\mathrm{SF}_{4}$ by XPS indepth mode.
XPS analyses also demonstrate that a 2D-FGM was deposited with a chemical gradient composition through the thin film thickness (Fig. 3). The fluorine content increases from the substrate/film interface to the outmost layer, although the carbon content does not have the same profile. An increase is observed in the first 100-200 nm near the substrate, and then the concentration stabilizes. This occurs simultaneously with the stabilization of the $\mathrm{Cr}$ con-

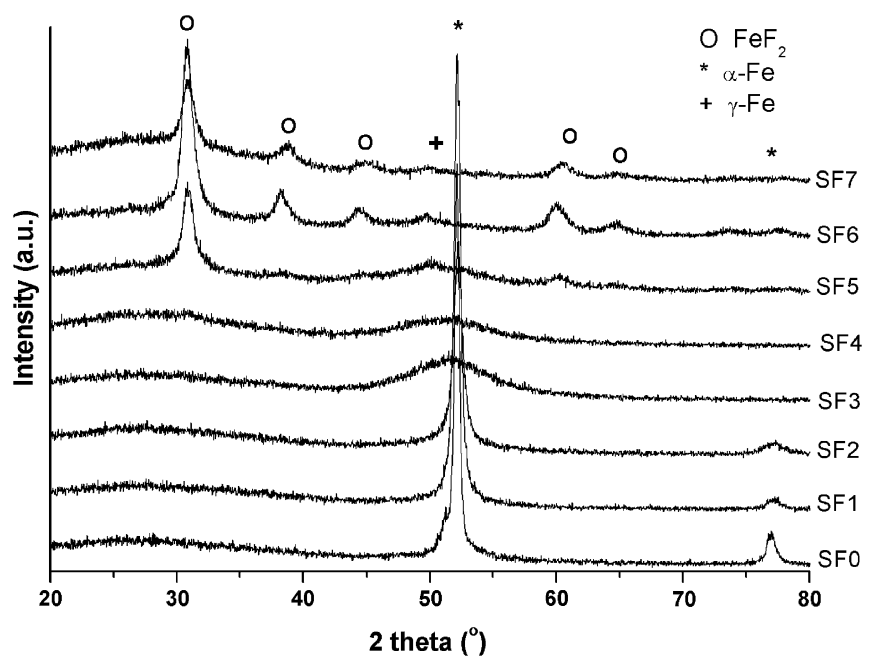

Fig. 4. Structural evolution with fluorine content evaluated by XRD. 
Table 2

Mechanical properties of the thin films of 316SS co-deposited with PTFE in inert atmosphere

\begin{tabular}{|c|c|c|c|c|c|c|}
\hline \multirow[t]{2}{*}{ Film } & \multicolumn{2}{|c|}{ Hardness $(\mathrm{GPa})$} & \multicolumn{2}{|c|}{$\sigma(\mathrm{GPa})$} & \multicolumn{2}{|c|}{ Adhesion (N) } \\
\hline & Mean & $\mathrm{SD}$ & Mean & $\mathrm{SD}$ & Mean & $\mathrm{SD}$ \\
\hline $\mathrm{SF}_{0}$ & 11.2 & 0.3 & -0.1 & 0.05 & $>70$ & - \\
\hline $\mathrm{SF}_{1}$ & 11.6 & 0.3 & -0.1 & 0.04 & 23 & 2 \\
\hline $\mathrm{SF}_{2}$ & 9.6 & 0.3 & -1.0 & 0.3 & 22 & 1 \\
\hline $\mathrm{SF}_{3}$ & 8.8 & 0.2 & -2.2 & 0.8 & $>70$ & - \\
\hline $\mathrm{SF}_{4}$ & 8.3 & 0.3 & -2.2 & 0.8 & 61 & 1 \\
\hline $\mathrm{SF}_{5}$ & 8.2 & 0.2 & -0.3 & 0.1 & 13 & 1 \\
\hline $\mathrm{SF}_{6}$ & 8.4 & 0.5 & -0.7 & 0.2 & 18 & 2 \\
\hline $\mathrm{SF}_{7}$ & 7.5 & 0.4 & -1.3 & 0.4 & 2 & 1 \\
\hline
\end{tabular}

centration. Once again, the presence of $\mathrm{C}$ in the compounds of the thin films is regulated by the presence of $\mathrm{Cr}$.

The structural features of the SF thin films are displayed in Fig. 4. The $\mathrm{SF}_{0}$ thin film exhibits a body-centered cubic (bcc) iron structure with a (1110) preferential orientation, in agreement with other authors' results [28]. SS316L is known to be an austenitic stainless steel that can transform, totally or partially, into martensitic steel at temperatures $\mathrm{Md}>25^{\circ} \mathrm{C}$ if submitted to stress ( $\mathrm{Md}$ denotes the beginning of martensitic transformation by deformation). This metallic alloy, when sputtered in a non-reactive mode, gives rise to ferritic structures such as in these thin films, for carbon contents similar to those of the bulk material. However, as the $d_{\text {dep }}$ of the PTFE target increases to $0.6 \mathrm{~W} \mathrm{~cm}^{-2}$ an important increase in carbon occurs, and a face-centered cubic (fcc) (111) structure is observed. This highlights the role of carbon as a stabilizing element of the gamma phase in bulk material (decreasing Md to values lower than room temperature) and has already been registered in thin films by other authors [29]. For the envisaged application, where the presence of ferromagnetic materials is forbidden, it is necessary to promote this structural transition. The structural evolution is also accompanied by a decrease in the apparent crystallite grain size which gradually leads to amorphization of the structure for the $\mathrm{SF}_{4}$ thin film $(F=20$ at.\%). For higher fluorine concentrations, the ordered structure of the thin films is mainly constituted by the $\mathrm{FeF}_{2}$ phase. The formation of iron fluoride in detriment of chromium fluoride has also been observed by other authors who implanted fluoride ions into stainless steel [30].

\subsection{Mechanical properties}

The mechanical properties evaluated for the as-deposited thin films are listed in Table 2. The highest microhard-
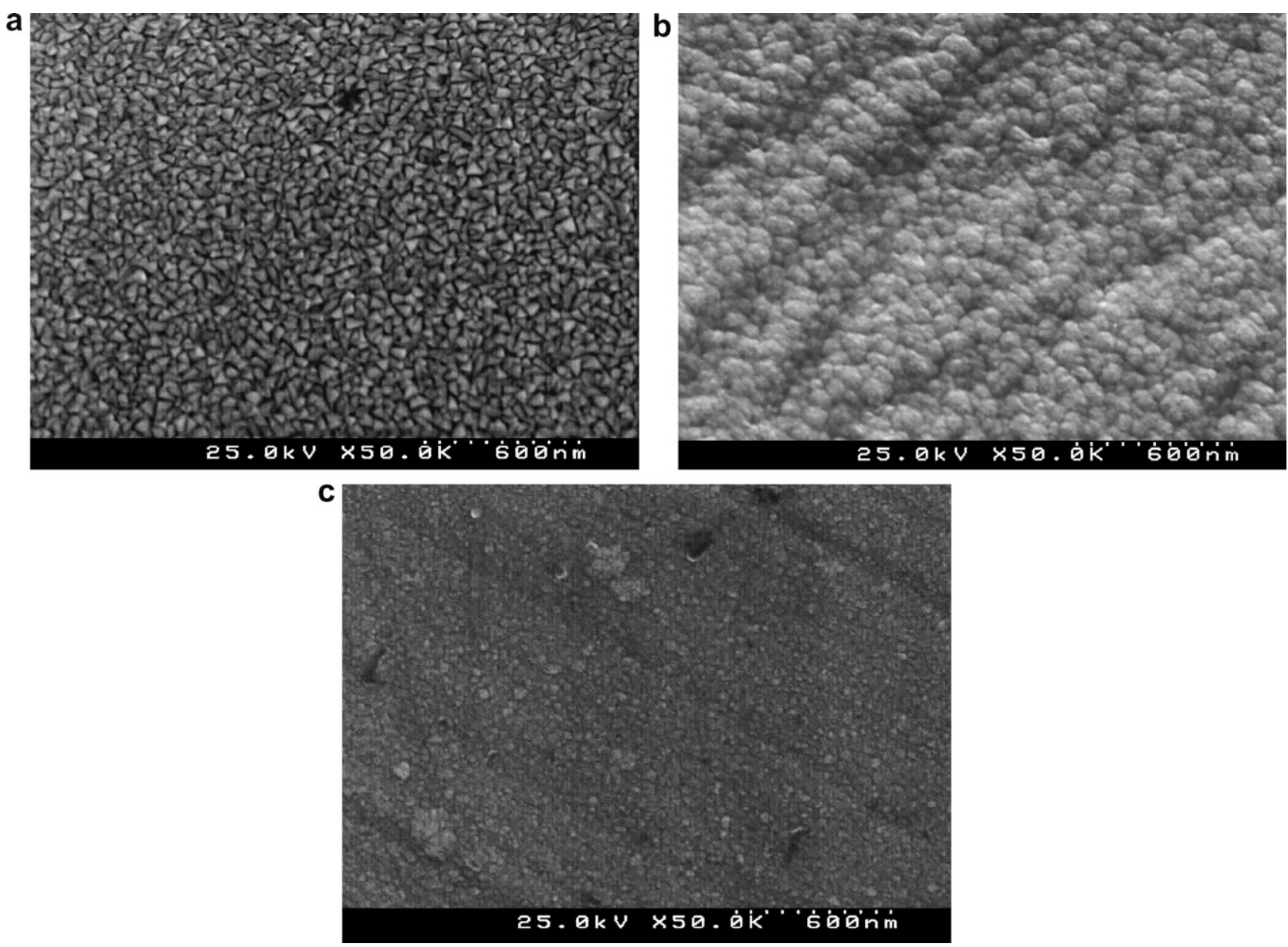

Fig. 5. Surface morphology evolution with fluorine content: (a) $\mathrm{SF}_{0}$; (b) $\mathrm{SF}_{3}$; and (c) $\mathrm{SF}_{7}$. 


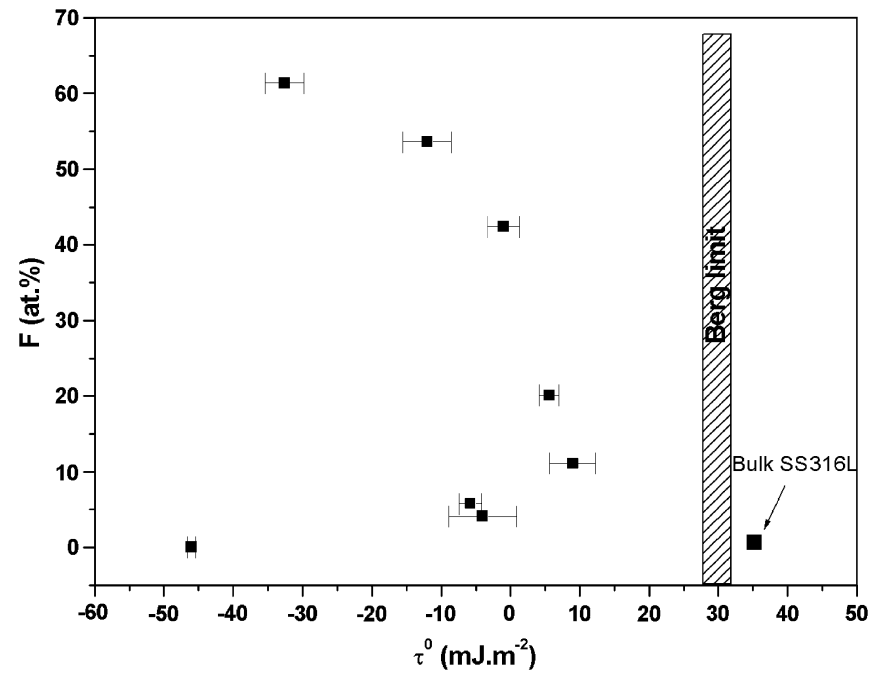

Fig. 6. Evolution of water adhesion tension of the surface of the functionally graded coatings.

ness value occurs for the $\mathrm{SF}_{1}$ thin film, which corresponds to the system with the highest chromium carbide content. As the carbon increases, the hardness decreases owing to the appearance of the iron carbide phase. This compound was not detected in the XRD diffractograms, but was clearly identified during XPS analysis. Also, the ternary phase diagram of $\mathrm{Fe}-\mathrm{Cr}-\mathrm{C}$ [31] predicts that, for a constant chromium concentration $(\sim 13$ at. $\%)$, the increase in carbon promotes the formation of $\mathrm{Fe}_{3} \mathrm{C}$ to the detriment of chromium carbides. These have greater hardness than $\mathrm{Fe}_{3} \mathrm{C}$ (between 10 and $16 \mathrm{GPa}$ for chromium carbides and $9 \mathrm{GPa}$ for iron carbide [32]), which could explain the decrease in hardness. Nevertheless, with the formation of the ceramic phase $\mathrm{FeF}_{2}$, the hardness value was predicted to attain higher values. But, owing to the brittle nature of the ceramic material, the reason for these low measurements may be apparent, as the microhardness impression during the evaluations is surrounded by extensive microcracking of the film. Also for SF6 and SF7, the XPS analysis highlighted the presence of graphitic carbon, which also contributes to the decrease in hardness present in these 2D-FGMs.

The residual stress state of the deposited thin films is compressive, which is expected in sputtered thin films harder than the substrate. It should be pointed out that the increase in residual stress in SF3 and SF4 should induce a martensitic structure, as already mentioned. The high carbon content is responsible for the inversion of the natural phase composition, as explained previously. Studies [33] show that growth stress in sputtered thin films is affected by deposition parameters such as argon pressure, substrate bias, deposition rate, substrate temperature and film thickness. In this study, none of the parameters was changed during the different depositions of the thin films studied. The compressive nature of the growth stress of these thin films is appropriate for applications under load, such as stents.

Another important mechanical characteristic is the adhesion of the deposited thin films to the substrate, which was evaluated by a dynamic indentation test. The adhesion values (Table 2) show that $\mathrm{SF}_{3}$ and $\mathrm{SF}_{4}$ present excellent adhesion to the substrate, as is the case with $\mathrm{SF}_{0}$. As the $\mathrm{F}$ content increases, the adhesion values decrease gradually until a very low value was attained for the $\mathrm{SF}_{7}$ thin film. This behaviour can be attributed to the increased content of brittle $\mathrm{FeF}_{2}$.

From the evaluated chemical and mechanical properties, the $\mathrm{SF}_{3}$ and $\mathrm{SF}_{4}$ thin films are the ones that have the most suitable characteristics for use in the modification of SS316L stents.

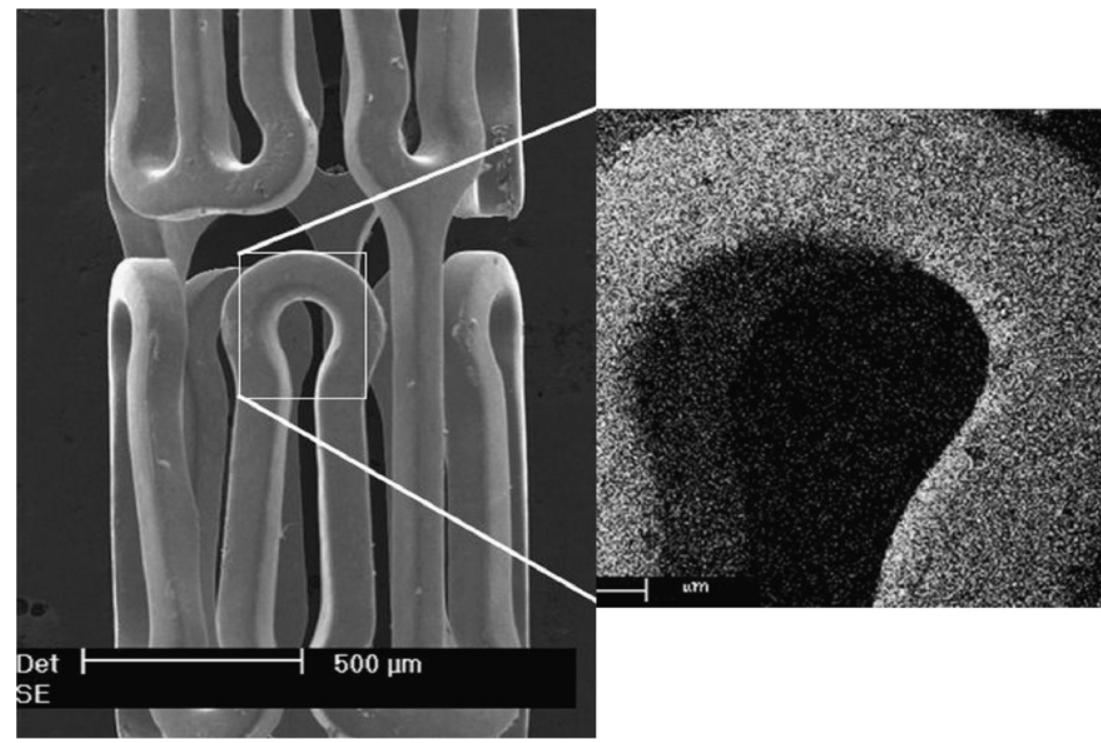

Fig. 7. SEM image and fluorine elemental map distribution of a stainless steel stent modified with SF4 thin film. 


\subsection{Surface characteristics}

The surface morphology of representative modified surfaces of the SF system is shown in Fig. 5, and it is clear that the increase in $\mathrm{F}$ and $\mathrm{C}$ content induces smoother surfaces. Moreover, with the increase in fluorine content, the crosssectional morphology becomes featureless. This densification, along with the strong adhesion measured in some thin films, allows the 'new' surface to act as a barrier between the aggressive biological media and the metallic substrate, thus preventing corrosion phenomena. It is also clear that the surface of $\mathrm{SF}_{0}$ thin film consists of needle-like grains, which are typical of a martensitic morphology [34]. The density of these grains decreases with the increase in power deposition of the PTFE target, giving rise to the appearance of round grains, characteristic of austenitic morphology.

The surface topography allows the wettability of the 2DFGM to be measured without constraints induced by high roughness values, which have a dramatic influence on the contact angle results. The contact angle value with pure water (with $\gamma^{0}$ values very similar to simulated body fluids) can be used to determine water adhesion tension $\left(\tau^{0}=\gamma^{0} \cos \theta\right)$ [35]. The ability of the 'new' surface to activate the blood plasma coagulation cascade, protein adsorption and the attachment of cells can all be predicted using this parameter derived from the water contact angle. The surfaces of interest for the final objective of this work should have $\tau^{0}$ below the Berg limit $\left(\tau^{0}<30 \mathrm{~mJ} \mathrm{~m}^{-2}\right)$ so that they support some protein adsorption, inhibit the coagulation cascade and are not favourable for cell attachment. All the modified surfaces have $\tau^{0}$ values below the Berg limit, unlike the bulk SS316L (Fig. 6), thus a reduction in restenosis and thrombus formation on the "new surfaces' can be predicted when compared with the bulk material. The indications given by these characterizations are currently being tested in dynamic protein adsorption tests as well as in vitro by cell culture. If the results match the predictions made from the $\tau^{0}$ values, this could be used as a rapid screening test before the usual in vitro tests.

\section{Conclusions}

Thin films of 316L stainless steel were successfully codeposited with PTFE by RF magnetron sputtering onto SS316L substrates and were characterized in the as-deposited state. The thin films were deposited according to a chemical gradient strategy (2D-FGM) in order to optimize the deposition parameters that lead to excellent adhesion between the thin film and the underlying substrate. Depending on the deposition parameters, adhesion $>70 \mathrm{~N}$ was obtained. All the new surfaces exhibited compressive internal stress, which is compatible with the expansion/flexion of modified stents. With increasing $d_{\text {dep }}$ of the PTFE target, the main structure evolves from $\alpha-\mathrm{Fe}+\mathrm{Cr}_{x} \mathrm{C}_{y} \rightarrow$ $\gamma-\mathrm{Fe}+\mathrm{Cr}_{x} \mathrm{C}_{y}+\mathrm{Fe}_{3} \mathrm{C}+\mathrm{FeF}_{2} \rightarrow \gamma-\mathrm{Fe}+\mathrm{FeF}_{2}+\mathrm{C}_{\text {gra }}$. The thin film that had chromium carbides but no iron carbide exhibited the greatest hardness ( $\sim 12 \mathrm{GPa})$. All the thin films exhibit water adhesion tension values $\left(\tau^{0}\right)$ lower than the Berg limit $\left(\tau^{0}=30 \mathrm{~mJ} \mathrm{~m}^{-2}\right)$, which are promising results for the application of these surfaces to prevent restenosis and thrombus formation at the site of stent implantation. From all the deposited and characterized surfaces, the $\mathrm{SF}_{3}$ and $\mathrm{SF}_{4}$ seem to be the most appropriate for the envisaged application. Moreover, the chosen technology is effective in the surface modification of a real $316 \mathrm{~L}$ stainless steel stent, which is clearly revealed by the fluorine elemental map distribution (Fig. 7).

\section{Acknowledgments}

This work was financially supported by Fundação para a Ciência e a Tecnologia (POCI/CTM/55967 and BPD/ 27139/2006) co-funded by European Union through FEDER.

\section{References}

[1] Duda SH, Wiesinger B, Koenig C, Wiskirchen J, Dietrich T, Tepe G. A clinical survey of vascular stents. Min Invas Ther Allied Technol 2002;11:193-201.

[2] Tepe G, Wendel HP, Khorchidi S, Schmehl J, Wiskirchen J, Pusich B, et al. Thrombogenicity of various endovascular stent types: an in vitro evaluation. J Vasc Inter Radiol 2002;13:1029-35.

[3] Sprague EA, Luo J, Simon C. Endothelial cell migration onto metal stent surfaces under static and flow conditions. J Long-Term Eff Med Implants 2000;4:97-110.

[4] Beier F et al. First in-human randomized comparison of an anodized niobium stent versus a standard stainless steel stent. Clin Res Cardiol 2006;95(9):455-60.

[5] Sketch $\mathrm{MH}$ et al. Evaluation of the Medtronic (driver) cobaltchromium alloy coronary stent system. Am J Cardiol 2005;95:8-12.

[6] Lau KW et al. Clinical impact of stent construction and design in percutaneous coronary intervention. Am Heart J 2004;147:764-73.

[7] Venkatraman S, Poh TL, Vinalia T, Mak KH, Boey F. Collapse pressures of biodegradable stents. Biomaterials 2003;24:2105-11.

[8] Park SJ, Lee CW, Hong MK, Kim JJ, Park SW, Tahk SJ, et al. Comparison of gold-coated NIR stents with uncoated NIR stents in patients with coronary artery disease. Am J Cardiol 2002;89:872-5.

[9] Kastrati A, Schomig A, Dirschinger J, Mehilli J, von Welser N, Pache $\mathrm{J}$, et al. Increased risk of restenosis after placement of gold-coated stents: results of a randomized trial comparing gold-coated with uncoated steel stents in patients with coronary artery disease. Circulation 2002;101:2478-83.

[10] Serruys PW et al. Randomised comparison of implantation of heparin-coated stents with balloon angioplasty in selected patients with coronary artery disease. Lancet 1998;352:673-81.

[11] Bakhai A et al. The SV stent study: a prospective, multicentre, angiographic evaluation of the BiodivYsio phosphorylcholine coated small vessel stent in small coronary vessels. Int $\mathbf{J}$ Cardiol 2005;102:95-102.

[12] Airoldi Flavio et al. Comparison of diamond-like carbon-coated stents versus uncoated stainless steel stents in coronary artery disease. Am J Cardiol 2004;93:474-7.

[13] Morrison ML, Buchanan RA, Liaw PK, Berry CJ, Brigmon RL, Riester L, et al. Diam Relat Mater 2006;15:138-46.

[14] Elezi S, Dibra A, Schomig A, Kastrati A. Current drug-eluting stents in complex patients and lesions. Miner Cardioangiol 2006;54:5-22.

[15] Rodgers CD. Drug-eluting stents: role of stent design, delivery vehicle, and drug selection. Rev Cardiovasc Med 2002;3(Suppl 5): S10-5. 
[16] Jérôme C, Aqil A, Voccia S, Labaye D-E, Maquet V, Gautier S, et al. Surface modification of metallic cardiovascular stents by strongly adhering aliphatic polyester coatings. J Biomed Mater Res A 2005;76:521-9.

[17] Koromila G, Michanetzis GPA, Missirlis YF, Antimisiaris SG. Heparin incorporating liposomes as a delivery system of heparin from PET-covered metallic stents: effect on haemocompatibility. Biomaterials 2006;27:2525-33.

[18] Hassel T, Bach F-W, Krause C, Wilk P. Corrosion protection and repassivation after deformation of magnesium alloys coated with a protective magnesium fluoride layer. Magnesium Technol 2005:485-90.

[19] EN 1071-3:2005. Advanced technical ceramics - methods of test for ceramic coatings. Part B: Determination of adhesion and other mechanical failure modes by a scratch test; 2005 .

[20] EN ISO 14577-4:2007. Metallic materials - instrumented indentation test for hardness and materials parameters. Part 4: Test method for metallic and non-metallic coatings; 2007.

[21] Antunes JM, Cavaleiro A, Menezes LF, Simões MI, Fernandes JV. Ultra-microhardness testing procedure with Vickers indenter. Surf Coat Technol 2002;149:27-35.

[22] Piedade AP. Biomaterials and sputtering. PhD Thesis. Coimbra: University of Coimbra; 2000. p. 78.

[23] Favia P, D'Agostino R. Plasma treatments and plasma deposition of polymers for biomedical applications. Surf Coat Technol 1998;98:1102-6.

[24] Lide DR. Handbook of chemistry and physics. 85th ed. Boca Raton, FL: CRC Press; 2004

[25] Keykamp H. Thermodynamic studies on chromium carbides by electromotive force (emf) method. J Alloy Compd 2001;321:138-45.
[26] Makimura Y, Rougier A, Tarascon JM. Pulsed laser deposited iron fluoride thin films for lithium-iron batteries. Appl Surf Sci 2006;252:4587-92.

[27] Latha G, Rajendrau N, Rajesware S. Influence of alloying elements on the corrosion performance of alloy 33 and alloy 24 in seawater. J Mater Eng Perform 1997;6:743-8.

[28] Zhang X, Misra A, Schulze RK, Wetteland CJ, Wang H, Nastasi M. Critical factors that determine face-centered cubic to body-centered cubic phase transformation in sputter-deposited austenitic stainless steel films. J Mat Res 2004;19:1696-702.

[29] Billard A, Steinmetz J, Frantz C. Sputtered stainless steel-carbon coatings as a substitute for hard electrolytic chromium for potential applications in mechanics. Mat Sci Eng A 1991;140:802-8.

[30] Hanamoto K, Sasaki M, Miyashita T, Kido Y, Nakayama Y, Kawamoto Y, et al. Effect of fluorine implantation on the microstructure and microhardness of AISI440C stainless steel. Nucl Instrum Meth B 1997;129:228-32.

[31] Baker H. ASM handbook, vol. 3. Materials Park, OH: ASM International; 1992.

[32] Goldschmidt HJ. Interstitial alloys. London: Butterworths; 1967, p. 92-9.

[33] Godbole MJ, Pedraza AJ, Park JW, Geesey G. The crystal structures of stainless steel films sputter-deposited on austenitic stainless steel substrates. Scripta Metall Mater 1993;28:1201-6.

[34] Inoue S, Saeki T, Uchida H, Koterazawa K, Iwasa M. Effects of ion flux on the properties of dc magnetron-sputtered stainless steel films. Vacuum 2002;66:257-61.

[35] Vogler EA. Structure and reactivity of water at biomaterial surfaces. Adv Colloid Interf Sci 1998;74:69-117. 